\title{
Subsurface deformation mechanisms beneath a flexible pavement using image correlation
}

\author{
A. J. BOWMAN* and S. K. HAIGH $\dagger$
}

\begin{abstract}
Flexible pavement structures are widely used in road construction, especially in circumstances where very high traffic volumes are not expected. These structures comprise of multiple layers of granular material, generally having decreasing strength with depth. Failure of these systems is typically observed as rutting on the ground surface, but the failure instigates at depth. In this research, for the first time, observations can be directly made of the progressive failure of these deeper layers under repeated wheel loading due to the combination of a new test apparatus, the Cambridge Accelerated Pavement Tester (APT), and Digital Image Correlation (DIC) technology. The use of a window allowing observation of soil displacements at depth during repeated wheel loading cycles allows the progressive failure to be observed and the changes in soil displacements and strains with different layer thicknesses to be quantified. It was observed that the critical failure mechanisms for thin and thick surficial layers are different, resulting in changes in the rates of surface rutting. Understanding these deformation mechanisms potentially allows savings to be made in road or airfield construction by using correctly-sized structural layers.
\end{abstract}

KEYWORDS: Pavements \& roads; deformation; full-scale tests; strain; limit state design/analysis

\section{INTRODUCTION}

A flexible pavement, so named for its ability to flex with loading, typically consists of four layers as seen in Figure 1. Wheel loads are applied to the surface layer through a series of progressively weaker layers composed of non-linear granular material to the compacted, in-situ soil, known as the subgrade. Layer thickness varies widely depending on initial input variables; elements such as materials, magnitude and number of repetitions of traffic loads, environmental conditions, and the desired service life must be considered (Brown, 1996). The influence, variability, and quantity of these input parameters, and the non-linear behaviour of the materials, has made standardised design of flexible pavements challenging, and, in many cases, entirely reliant on engineering judgement and empirical methods. High-volume flexible pavements typically benefit from some combination of standardised, mechanistic-empirical design methods utilising these factors; lightly trafficked road, however, more commonly draw on past experience and local practice (Brown, 2013). An understanding of the gradual, in-service failure mechanisms would represent a significant move towards simple, but effective, mechanistic flexible pavement design.

Failure of a pavement structure, precipitated by the cyclic loading of the granular material, is generally classified in two ways: resilient (recoverable) deformation, which leads to surface fatigue cracking, and plastic (permanent) deformation (Lekarp et al., 2000a,b). Permanent strain resulting from a single load cycle is generally very small, however its progressive accumulation leads to excessive vertical surface depressions known as rutting (Werkmeister et al., 2001). To understand these failures, analysis of pavement structures is typically broken into separate elastic and plastic models instead of using a single elasto-visco-plastic models more typical of monotonic geotechnical problems.

A review of flexible pavement literature shows that since the first mechanistic design attempts in 1962, the majority

\footnotetext{
Manuscript received. ..

* Department of Engineering, University of Cambridge, Cambridge, UK (Orcid: 0000-0001-6457-647X).

$\dagger$ Department of Engineering, University of Cambridge, Cambridge, UK (Orcid: 0000-0003-3782-0099).
}

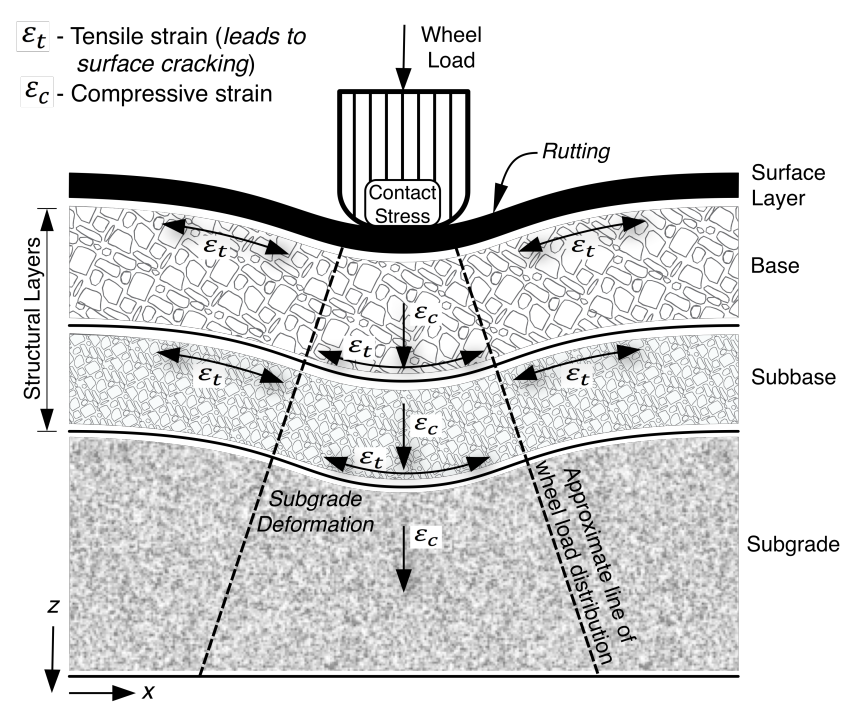

Fig. 1. Typical structure, strain profile, and failures (in italics) seen in a flexible pavement

of research effort has focused on the surface layer (Brown, 1996). Subsurface failure mechanisms and cumulative strain through the support layers to the subgrade is still not well understood. This is surprising given that previous research has shown that 30 to $70 \%$ of surface rutting is generated in the lower granular layers (Qiao et al., 2015). This means that understanding of permanent strain accumulation behaviour is essential for accurate performance prediction (Boulbiband \& Collins, 2015).

The current state of practice employs a number of elastic layer theories for the design of flexible pavements. Serviceability can be simply predicted by axial strain given a number of load cycles, while more advanced examples incorporate some element of applied stress (Lekarp \& Dawson, 1998). In service the granular materials supporting traffic loading are subject to cycles of vertical, horizontal, and shear stress causing deformations unique to each individual layer. Some questions have been raised about the applicability of 
deformation models developed from standard triaxial test data as the influence of principle stress rotation is not considered. More advanced mechanistic design methods have hence been developed from repeat load triaxial (RLT) tests and limit state design known as Shakedown (Werkmeister et al., 2001). However, even these more advanced element tests fail to capture all the stresses unique to flexible pavement systems.

Along the travel path, shear stress is rotated as the load traverses causing a rotation of the principal stress axes within the soil (Lekarp \& Dawson, 1998). Jeffries et al. (2015) and Gräbe \& Clayton (2009) found that cyclic principle stress rotation softens soil causing significantly larger cumulative strain and accelerated failure. As a result, researchers (Steyn, 2012; Korkiala-Tanttu, 2009) have moved to accelerated pavement testing as a way to reliably replicate the stresses seen in layered, flexible pavement systems in order to find correlation with permanent strain and number of cycles.

The bulk of full scale modelling concentrates on information provided by the surface layer response. Whilst subsurface deformations at discrete points can be measured using instruments such as settlement tubes and strain coil sensors, these results are rarely reported. Further, because these instruments do not give the deformation field, these methods have no way of determining which specific failure mechanism is responsible for the deformation. Failure mechanisms similar to those suggested by Vesic (1963), as seen in Figure 2, would suggest shear failure is responsible for the surface deformations and ultimate strength methods (Prandtl, 1920) could be applied. However, experimental verification is lacking.

In Cambridge, a new accelerated pavement tester (APT) which utilises digital image correlation (DIC) has been constructed (Bowman \& Haigh, 2016). The main objective of this paper is to present results from the in-situ imaging of the deformation mechanisms and strain measurements seen in flexible pavement structures with various layer thicknesses.

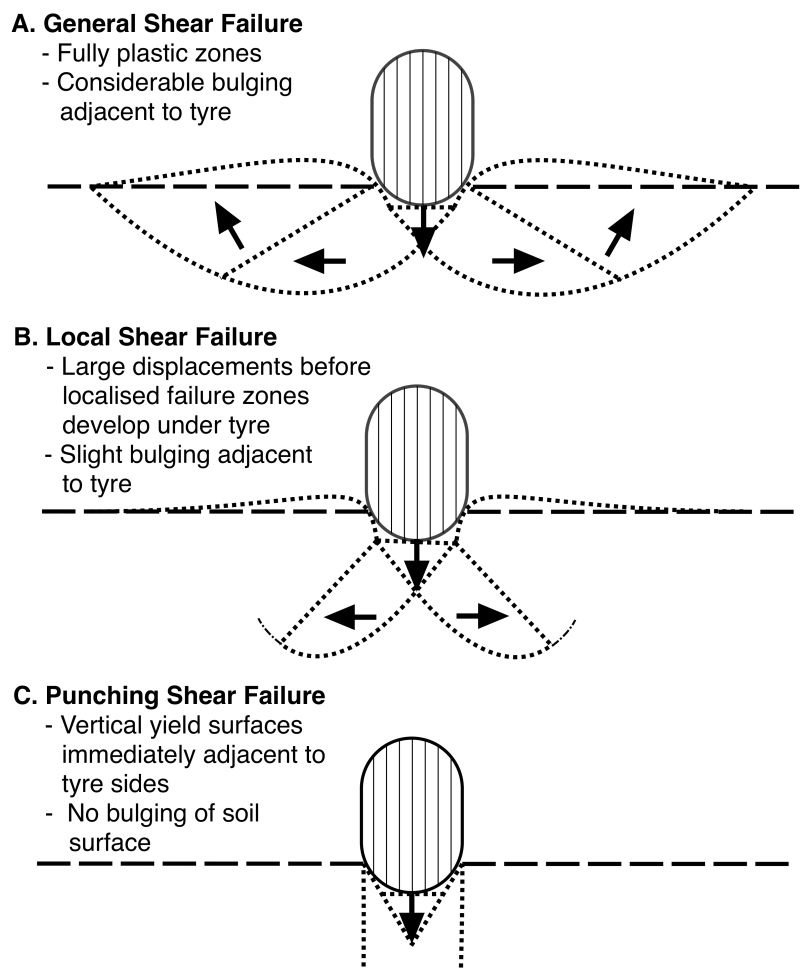

Fig. 2. Suggested failure modes beneath a single tyre
Using this data, comparisons to ultimate strength methods are assessed.

\section{EXPERIMENTAL METHODS}

Accelerated pavement testing replicates pavement stresses and facilitates the verification of theoretical concepts under controlled conditions in a compressed time period (Steyn, 2012). The laboratory environment has the added benefit of being able to repeat experiments, introduce novel instrumentation, and investigate unique materials.

This paper focuses on the progression of deformation throughout the entire depth of a pavement structure as the number of load cycles increased and the final failure mechanisms observed as a result. Two different APT tests are presented. The cross-sections of each test can be seen in Figure 3. Surface loading was accomplished through a solid rubber tyre which produced an elliptical contact patch. Instrumentation on the APT measured the applied load and the contact area at load was determined via a flexible, grid-based, tactile pressure sensor. The travel path of the tyre is $620 \mathrm{~mm}$, significantly larger than the width-at-load of the tyre indicating that plane strain conditions perpendicular to the tyre's travel path dominate. The load was centred in the model, with no incorporated wander, in order to replicate upper and lower bound conditions. The tyre is smooth resulting in minimal shear stress development on the surface. The average velocity was $1.8 \mathrm{~cm} / \mathrm{s}$ with a standard deviation of $\pm 0.19 \mathrm{~cm} / \mathrm{s}$. Test details relevant for analysis can be seen in Table 1 .

Table 1. Details of APT tests

\begin{tabular}{|c|c|c|c|c|c|}
\hline \multirow[b]{2}{*}{ Test ID } & \multicolumn{2}{|c|}{$\begin{array}{c}\text { Structural Layer } \\
\text { Thickness }\end{array}$} & \multirow[b]{2}{*}{$\begin{array}{c}\text { Average } \\
\text { Surface } \\
\text { Load } \\
(k N)\end{array}$} & \multirow[b]{2}{*}{$\begin{array}{c}\text { Surface } \\
\text { Pressure } \\
(k P a)\end{array}$} & \multirow[b]{2}{*}{$\begin{array}{c}\text { Number } \\
\text { of } \\
\text { Cycles }\end{array}$} \\
\hline & $\begin{array}{l}\text { Base } \\
(\mathrm{mm})\end{array}$ & $\begin{array}{l}\text { Subbase } \\
(\mathrm{mm})\end{array}$ & & & \\
\hline Test $1 \mathrm{~A}$ & 220 & 100 & 30.1 & 1,964 & 21,008 \\
\hline Test $2 \mathrm{~A}$ & 40 & 40 & 16.8 & 1,245 & 17,038 \\
\hline
\end{tabular}

The pavement structure was housed in a $1.4 \mathrm{~m}$ deep by 1 $\mathrm{m}$ wide by $1 \mathrm{~m}$ long concrete tank with one wall being a steel frame housing a poly methyl methacrylate (PMMA) window (commercially known as Perspex). The granular layers were installed in lifts and compacted using vibration to optimum modified proctor values. Three soils were used in these tests. The base course was a limestone aggregate with a $\mathrm{D}_{50}$ of $6 \mathrm{~mm}$. The subgrade was a natural sand-silt with a $\mathrm{D}_{50}$ of $0.30 \mathrm{~mm}$ and a fines content of $16.6 \%$. The subbase was a 50/50 mixture by weight of the base and the subgrade material. A bituminous surface layer was not used in these tests. Relevant results from a suite of material classification and triaxial consolidated-drained tests are presented in Table 2.

Table 2. Material properties for the layers used in testing and analysis

\begin{tabular}{llll}
\hline Soil Property & Base & Subbase & Subgrade \\
\hline Cohesion $(k P a)$ & 0 & 2.3 & 7.4 \\
Friction angle, $\phi_{c r i t}^{\prime}$ & $38^{\circ}$ & $35^{\circ}$ & $31^{\circ}$ \\
Dry unit weight $\left(k N / m^{3}\right)$ & 16.1 & 18.3 & 19.0 \\
Dilation angle, $\psi$ & $26^{\circ}$ & - & $5.4^{\circ}$ \\
\hline
\end{tabular}



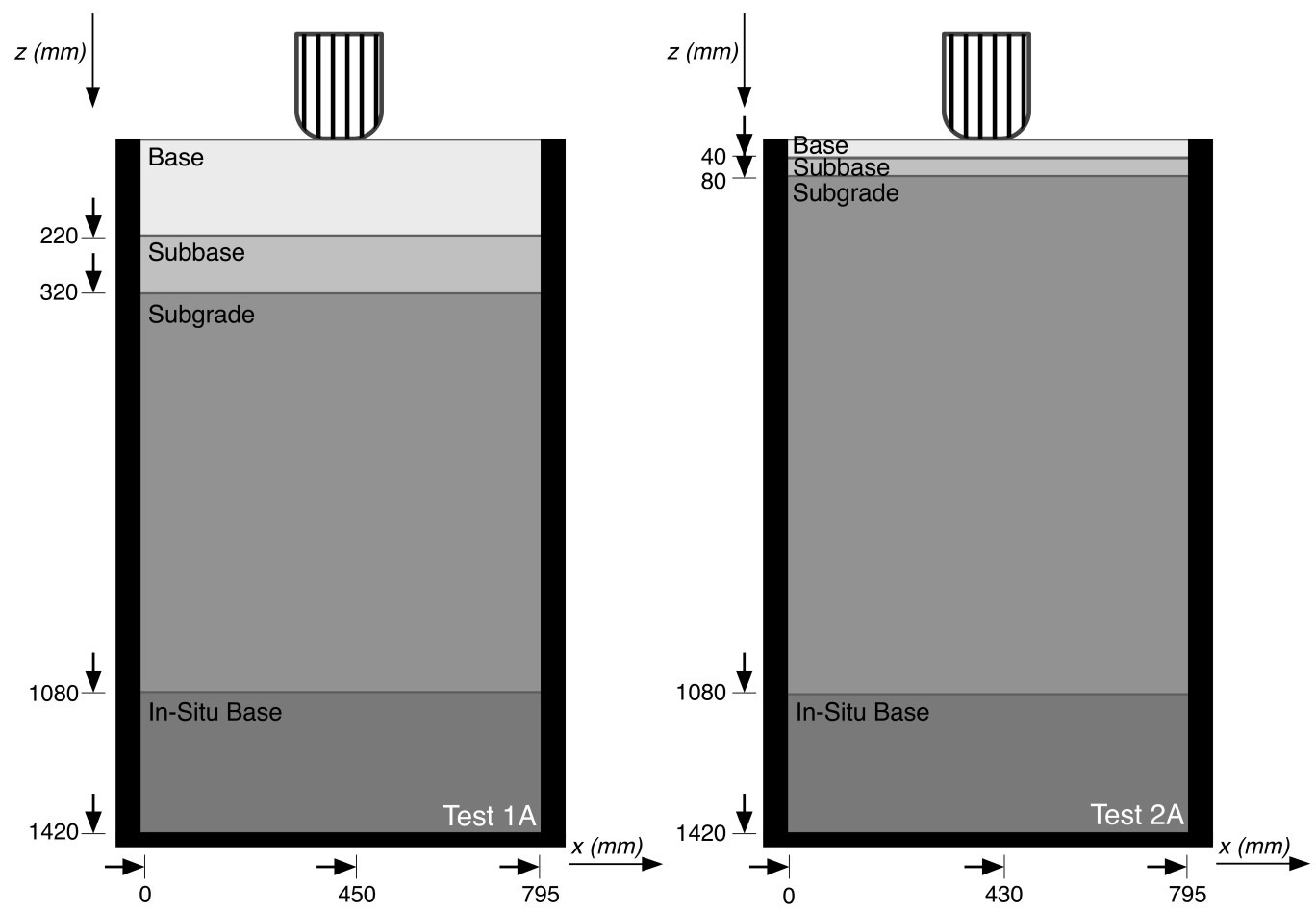

Fig. 3. Cross-section sketches of APT experiments

In similar research (Brown \& Chan, 1996; Werkmeister et al., 2001), the conclusions drawn about the causes of pavement rutting lack data from any subsurface measurement during the test. There is some qualitative data gained using posttest trenching perpendicular to an experiment's load path, which provides insight into the final plastic displacements and behaviour of the pavement materials (Gopalakrishnan, 2010). However, any measurement of dynamic strain or progressive accumulation is lost. The APT and the incorporation of DIC, alternatively, does quantitatively analyse the permanent deformation mechanisms at play beneath the pavement surface during each load cycle.

First used in the 1990s, image analysis has allowed geotechnical researchers to visualise previously unseen failure mechanisms, along with soil and soil-structure interactions, at a granular level (Stanier et al., 2015; White et al., 2003). The technique is ideally suited for geotechnical applications as both direction and magnitude of granular flow can be measured in strain ranges typically between $0.1 \%$ and $1 \%$, important because this is higher than the magnitude of error associated with the technique (Take, 2015). All soil types and movements can be tracked making it ideal for use in a layered pavement structure.

The images of the pavement's cross-section were taken through a $500 \mathrm{~mm}$ wide $\times 900 \mathrm{~mm}$ high $\times 125 \mathrm{~mm}$ thick Perspex window. A fixed, 4416 x 3312 pixel resolution camera was utilised for image acquisition together with on-glass, fixed control markers which were used for calibration and elimination of camera distortion. The areas monitored by the camera generally captured the depth of the model from $200 \mathrm{~mm}$ to $1000 \mathrm{~mm}$ below the surface and the width of the pavement model from $-250 \mathrm{~mm}$ to $200 \mathrm{~mm}$ relative to the centre of the tyre position. Images were taken as the loaded tyre approached the window; approximately $50 \mathrm{~mm}$ away (Figure 4). By tracking discretised soil patches from one image to another, permanent deformation could be determined as cycles increased. Analysis and construction of the deformation fields was performed using GeoPIV (White et al., 2003).

Figure 5, a typical result using data from Test 1A, shows the total displacement vector field of the soil patches against the window, or the plane strain movements perpendicular to the load. The raw data from a DIC analysis will typically have a number of erroneous vectors due to influence from the control markers or poor tracking due to loss of soil texture. As a result, these "wild vectors" have been removed and replaced with vectors linearly interpolated from the values of the surrounding patches. In Test $1 \mathrm{~A}, 5 \%$ of the vectors and in Test $2 \mathrm{~A}, 1 \%$ of vectors were "wild".

To counteract friction effects between the concrete walls and the various granular materials, methods outlined by Tognon et al. (1999) were used. The wall interfaces were lined with a

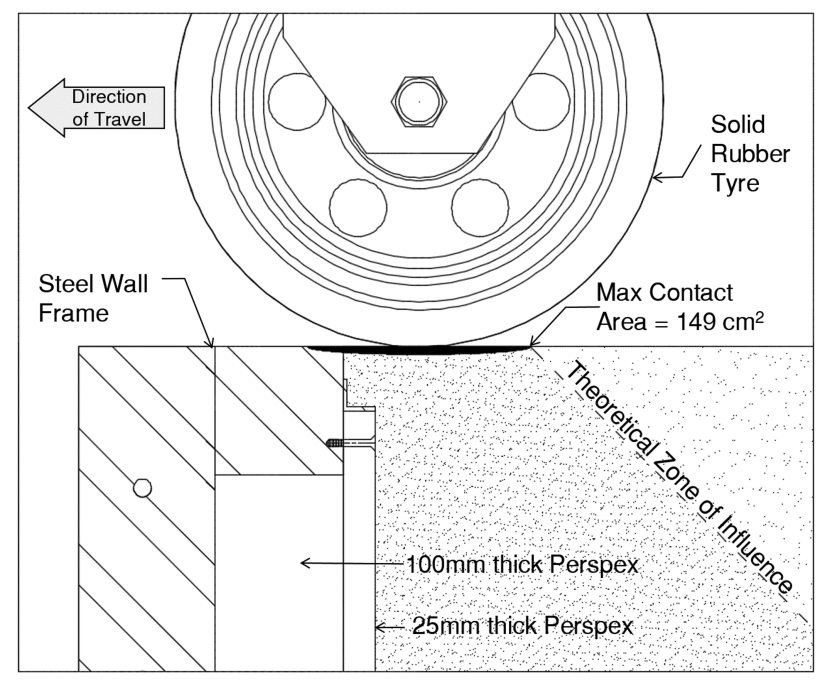

Fig. 4. Tyre location at wall 


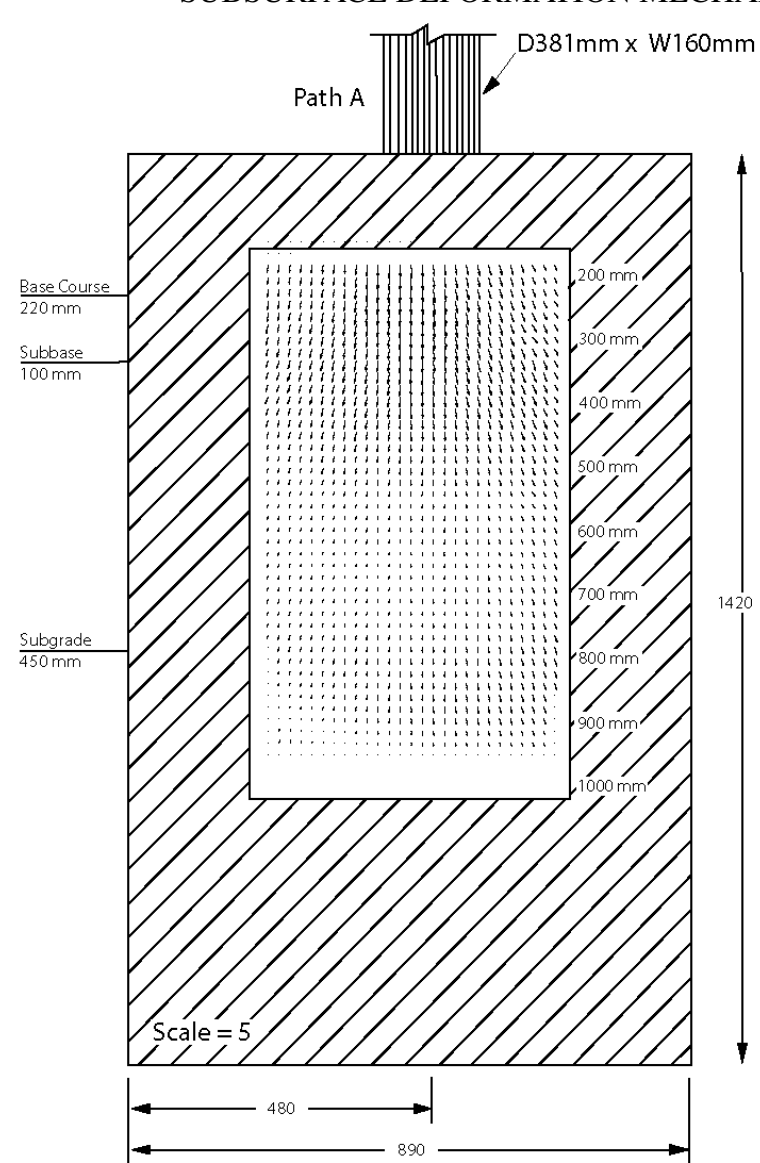

Fig. 5. Vector plot of Test $1 \mathrm{~A}$

combination of plastic sheeting, silicon grease, geomembrane, and geosynthetic to create a puncture-resistant, waterproof, lubricated sliding interface, which was shown by Tawfiq \& Caliendo (1993) to give a reduction in shear strength of 80 to $98 \%$. Similar shear box tests were performed between the specific soils used in these experiments and the soilgeomembrane interface. Additionally, the interface friction between the PMMA window and granular materials was also examined. Table 3 displays the results. Each test found that the frictional influence of the walls was less than that found for a soil-soil interface and therefore disregarded in subsequent displacement results.

Table 3. Peak shear stress ratio and friction angle of APT interfaces compared to soil interface

\begin{tabular}{|c|c|c|c|c|c|c|}
\hline \multirow{2}{*}{$\begin{array}{l}\text { Interface } \\
\text { Soil type }\end{array}$} & \multicolumn{2}{|c|}{ Soil/soil } & \multicolumn{2}{|c|}{$\begin{array}{l}\text { Soil/ } \\
\text { geomem- } \\
\text { brane }\end{array}$} & \multicolumn{2}{|c|}{$\begin{array}{l}\text { Soil/ } \\
\text { PMMA }\end{array}$} \\
\hline & $\frac{\tau_{\max }}{\sigma_{v}}$ & $\phi$ & $\frac{\tau_{\max }}{\sigma_{v}}$ & $\phi$ & $\frac{\tau_{\max }}{\sigma_{v}}$ & $\phi$ \\
\hline Base & 2.2 & $49^{\circ}$ & 0.05 & $2^{\circ}$ & 0.42 & $10^{\circ}$ \\
\hline Subgrade & 0.65 & $34^{\circ}$ & 0.025 & $1^{\circ}$ & 0.41 & $12^{\circ}$ \\
\hline
\end{tabular}

\section{DEFORMATION PROGRESSION}

The permanent deformation of a pavement has generally been attributed to four separate mechanisms: compaction, shear strain, deformation of subgrade, and particle crushing (Brown, 1996). The exact combination of compaction and shear in the unbound granular materials which leads to failure however remains elusive.
In this paper permanent deformation of a pavement structure will be examined in two ways: through surface and subsurface deformation. Two methods of deformation measurement were used: a laser scanner was incorporated to track rut development at the surface and DIC was used to measure sub-surface deformation fields in-situ.

\section{Surface Deformation}

Laser surface scanning is a common method of measuring surface deformation in pavement experiments. For this research, a laser mounted to a linear actuator controlled by a stepper motor was used to scan the pavement surface at set cycles. Using this scanner, progressive surface deformation perpendicular to the tyre was determined. The total deformation per cycle was found by subtracting the initial surface measurement from the current scan results at the centre of the tyre location.

From the surface scan data directly beneath the tyre (Figure 6) it is seen that layer thickness has altered deformation behaviour. In Test 1A, rutting progressed linearly as the number of load applications increased, suggesting steady plastic movement of the subsurface material. Upheaval on either side of the tyre into the free field indicated rotation of the principal stress direction from the active zone directly beneath the tyre to the passive zone on either side. At failure, Test $1 \mathrm{~A}$ experienced over $3 \mathrm{~mm}$ of gradual upheaval on both sides of the tyre.

The behaviour changed in Test 2A. Here, deformation increased in a non-linear fashion suggesting plastic, progressive failure. The final rut shape had nearly vertical sides and only $1 \mathrm{~mm}$ of upheaval adjacent to either side of the tyre. As this upheaval was limited, granular movement was likely constrained to the region directly beneath the tyre suggesting some combination of a punching shear mechanism and substantial, localised, volumetric strain.

In all tests the deformation did not stabilise, counter to the behaviour expected from RLT testing (Werkmeister et al., 2001). Brown \& Chan (1996) concluded that the moving wheel load generates shear stress within the soil causing large, progressive strains to develop. This is a more damaging stress regime than repeat loading and therefore larger deformations than those predicted by RLT would be expected. This demonstrates the value of accelerated pavement testing over traditional material testing methods.

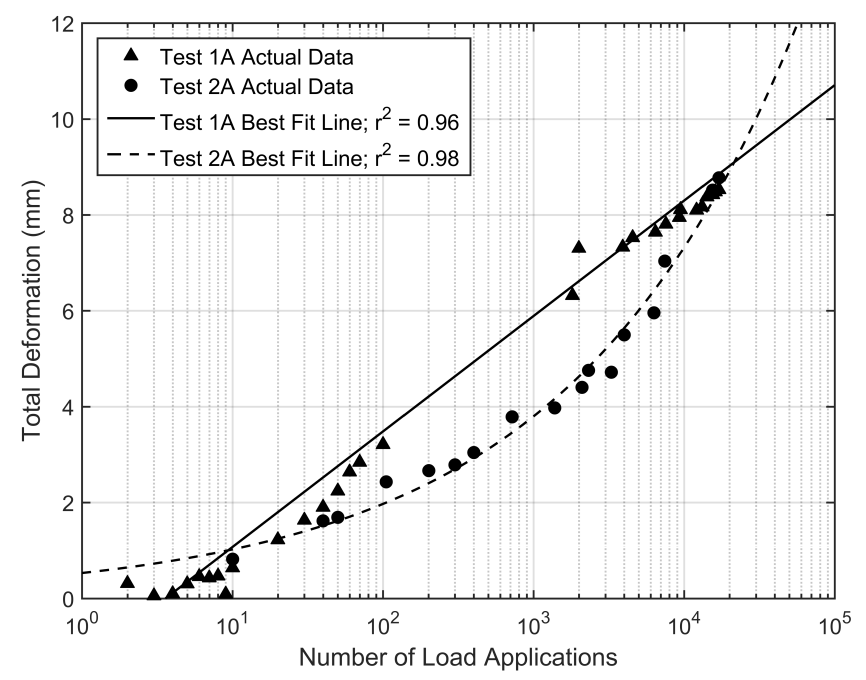

Fig. 6. Measured and predicted surface deformation under tyre with number of cycles 

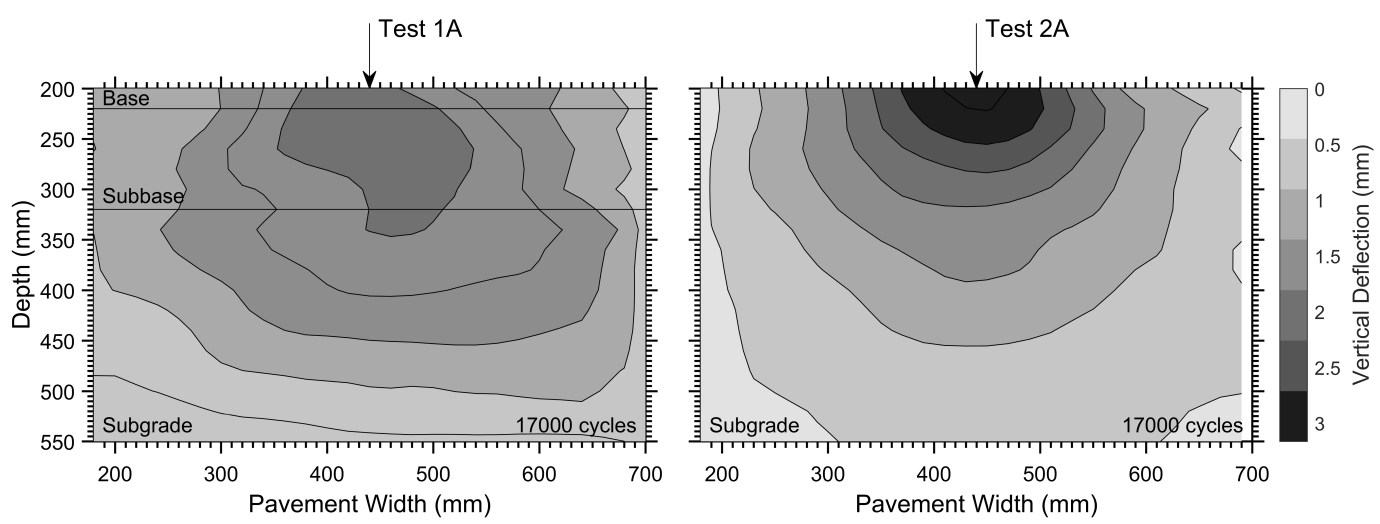

Fig. 7. Contours of accumulated vertical deformation at final cycle for each test
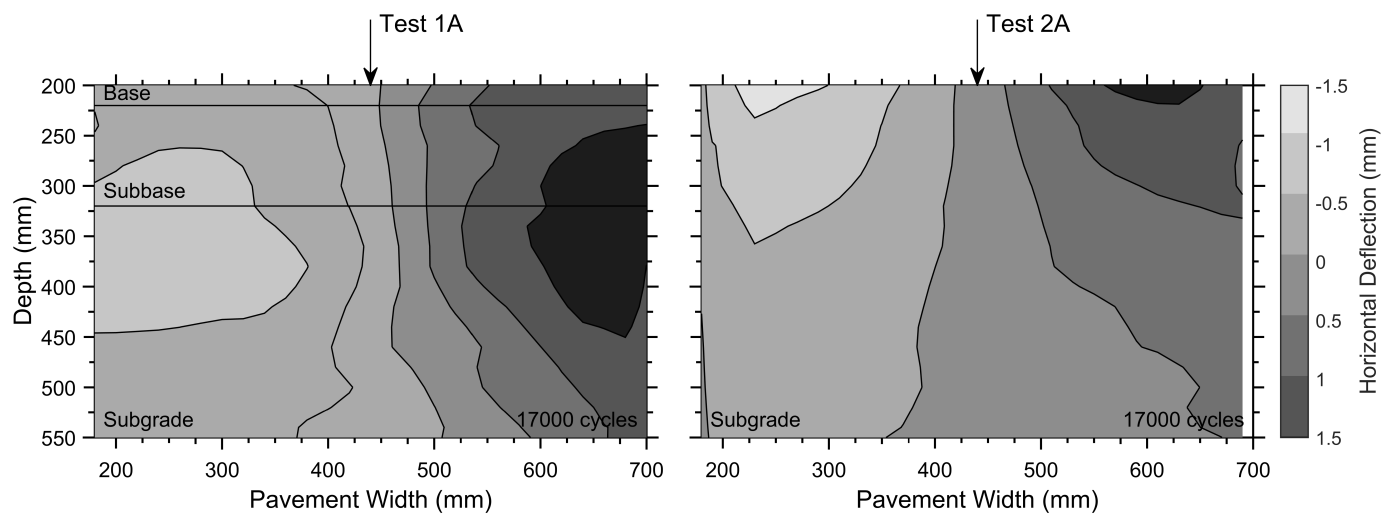

Fig. 8. Contours of accumulated horizontal deformation at final cycle for each test

In similar research (Brown \& Chan, 1996; Gopalakrishnan, 2010), the conclusions drawn about the causes of pavement rutting would lack substantiation by any subsurface measurement. The APT however, through the incorporation of DIC, can quantitatively analyse the deformation mechanisms at play beneath the surface.

\section{Subsurface Deformation}

In this section permanent subsurface displacements will be examined using the results from digital image correlation (DIC). Analysis of successive images created a progressive vector field corresponding to accumulated displacement of the patches through the cycles. To ease visualisation, the results of both tests are displayed as vertical and horizontal contour plots in Figures 7 and 8 respectively. Several phenomena suggested in the previous section by the surface scanning will be specifically examined.

Figure 7 is the accumulated vertical displacement of Test $1 \mathrm{~A}$ and Test $2 \mathrm{~A}$ after 17,000 cycles. In Test $1 \mathrm{~A}$ the effect on vertical displacement of the transition between the three layers is shown by observing the irregularities in the contour lines at those locations. The contour lines in Test $2 \mathrm{~A}$ are smooth as no layer boundaries are crossed within the viewing window. Further, it can be seen that in Test 1A the displacement is spread wider in each subsequent layer. The displacement in Test $2 \mathrm{~A}$ is more localised to the area directly beneath the tyre. As a comparison, at $200 \mathrm{~mm}$ depth in Test 1A the total vertical displacement is $2.1 \mathrm{~mm}$ which is $24 \%$ of the surface deformation at the same cycle. This suggests that the majority of the vertical movement seen at the surface was dissipated in the base course. At the same depth in Test $2 \mathrm{~A}$, the total vertical displacement is $3.3 \mathrm{~mm}$ which is $39 \%$ of the surface deformation at the same cycle with less applied load. The pavement system in Test $1 \mathrm{~A}$ is stronger than Test 2A, as to be expected. Limited interference from the sidewalls was noted in Figure 7.

The effect of reducing the structural layer's thickness on the displacement of the granular material is clear when comparing the depth of increased vertical deflection which penetrates deeper into the pavement in Test $2 \mathrm{~A}$ as opposed to Test 1A. The depth at which accumulated vertical deformation is less than $0.5 \mathrm{~mm}$ is $500 \mathrm{~mm}$ in Test $1 \mathrm{~A}$, whereas in Test $2 \mathrm{~A}$ it was substantially deeper, at $700 \mathrm{~mm}$.

In both tests the tyre is in the centre of the model. This was ideal for examining horizontal movement (Figure 8) of the granular layers into the free field either side of the tyre path. In both cases, there is limited horizontal movement directly beneath the tyre.

In Test 1A, the horizontal movement of the soil was confined primarily to the base layer above the view of the camera. Horizontal displacement below a depth of $200 \mathrm{~mm}$ was minimal and evenly distributed throughout the depth except when distance from the side walls reduced the rate of lateral movement. The thicker structural layers effectively acted to rotate the surface stress and distribute it through the upper layers so that minimal effect is is seen in the subgrade. Conversely, the horizontal movement in Test $2 \mathrm{~A}$ is localised higher. Below $200 \mathrm{~mm}$ the horizontal movement is very small confirming predictions from the surface observations that the movement in Test $2 \mathrm{~A}$ was primarily vertical and localised to the region directly beneath the tyre. 
Combined Results

To gain a better appreciation for the granular movement through the entire depth of the model, measurements taken at the surface and using DIC were combined at each cycle. Using triangulation-based linear interpolation a new grid was established allowing displacement between $50 \mathrm{~mm}$ and $150 \mathrm{~mm}$ to be examined. To demonstrate the efficacy of this method, the vertical strain under the tyre with depth is plotted for cycles 10 , $100,1,000,10,000$, and the maximum cycle for each respective test in Figure 9 using these results.

Examining the results of Test 1A (Figure 9) it can be seen that vertical strain slowed with number of cycles, yet from surface displacement measurements the plastic displacement under the tyre continued linearly through the duration of the test. This again points to another form of deformation occurring subsurface. In Test 2A the strain with cycles accelerated as the test progressed which aligns with the deformation seen at the surface.

Overall, the vertical strain at failure was approximately $50 \%$ greater in Test 2A than that which was seen in Test $1 \mathrm{~A}$. Knowing that the settlement at the surface was the same at 17,000 cycles for both tests, it shows again that the mechanisms had to be different due to the layer thicknesses. In Test $1 \mathrm{~A}$ it can be seen that the strain is confined to the base layer and the top half of the subbase which echos the vertical displacements seen in Figure 7. In Test 2A the strain reaches much deeper into the pavement structure. A sudden decrease in strain can be seen to occur between $100 \mathrm{~mm}$ and $200 \mathrm{~mm}$. This is thought to be the end of the conical failure wedge which formed beneath the tyre, which will be examined in more detail in later sections.

\section{A NOTE ON BOUNDARY EFFECTS}

Vertical displacement measurements captured no significant sign of interference due to sidewall friction against the window which would have manifested in the DIC data as a region of less vertical deformation than that seen from laser scans in the centre of the model. The two sets of data, when merged (for example Figure 9) show adequate correlation. Artificial stiffening due to the interaction between displacement and sidewall boundaries depended on the position of the tyre. DIC demonstrated that when the tyre was at the centre of the model, the vertical and horizontal displacement at the edge of the viewing frame was negligible, which was still an additional 150 $\mathrm{mm}$ from the concrete walls. However it could be argued that the boundary stiffness restricts the lateral movement of the soil, much like the finite boundaries of a true pavement. Ultimately the allowable width of the pavement structure is the major limitation of the APT but has been shown here to be negligible to the stated tests objectives.

\section{SHEAR AND VOLUMETRIC STRAIN OBSERVATIONS}

Current methodologies in pavement design attempt to redistribute the surface forces through the base and subbase, or structural, layers. By increasing the thickness of these layers the surface forces are reduced far enough to limit the vertical compressive strain at the top of the subgrade thereby avoiding permanent subgrade failure. From the results reviewed thus far, it was seen that Test $1 \mathrm{~A}$ successfully did this, while Test 2A did not. Layer thickness has been an important and steadfast flexible pavement design criteria for some time (Brown, 1996). However, experimentally, only the reduction of surface movement has provided any basis for the criteria. DIC has shown, so far, its potential use in understanding the subsurface granular movement and for development of more specific deformation response prediction. But the technique has further advantages in that the mechanisms causing the surface

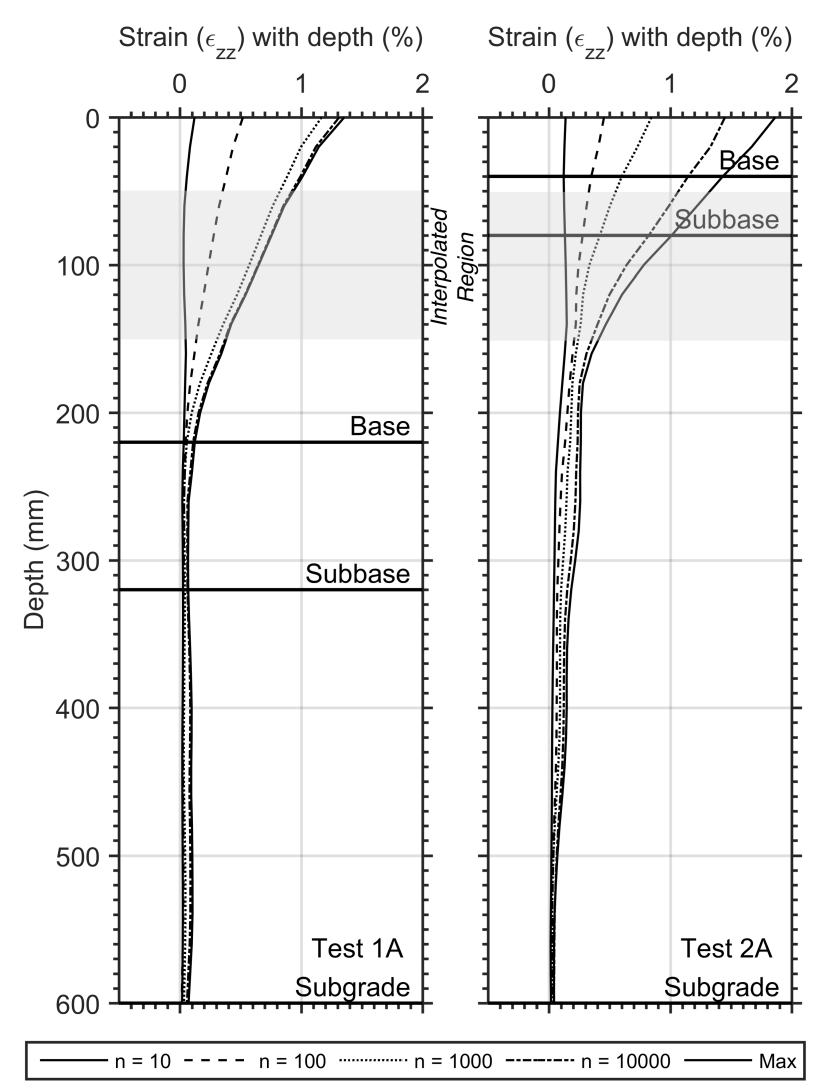

Fig. 9. Permanent volumetric strain with depth beneath the tyre for Test $1 \mathrm{~A}$ and Test $2 \mathrm{~A}$ for various cycles

deformation, and the influence of the granular material on these failure mechanisms can be investigated.

Shear and volumetric strain from the combined surface and DIC measurements will endeavour to breach these unknowns. Analysis will be conducted at 10,000 cycles. This cycle was chosen as it definitively showed the failure planes developing beneath the tyre in both tests. By failure, various strain contours were intersecting and lacked clarity.

In Figure 10 the shear and volumetric strain contours can be seen for Test $1 \mathrm{~A}$ at 10,000 cycles. Several observations can be made:

1. The majority of shear strain is localised in the base layer and only after approximately 10,000 cycles was failure planes beginning to form in the subbase layer.

2. The shear strain beneath the tyre reduces constantly with depth.

3. The shear strain within the base indicated that a failure wedge has formed beneath the tyre. These slip surfaces connect to horizontal shear planes seen just above the transition from the base to the subbase. This suggests that the failure surfaces connect the downward motion and spread outward. Slip surfaces such as these are typical of the general shear failure mechanism seen in Figure 2.

4. The slip surfaces formed are generally equivalent on both sides of the tyre demonstrating the load was applied squarely by the tyre.

5. Extensive research by De Beer et al. (1997) found that the typical vertical contact stress distribution of a smooth tyre was higher at the tyre's edges than at its centre. The shear strain directly beneath the tyre is greater at the edges than at the centre reflecting a similar contact pressure distribution. 

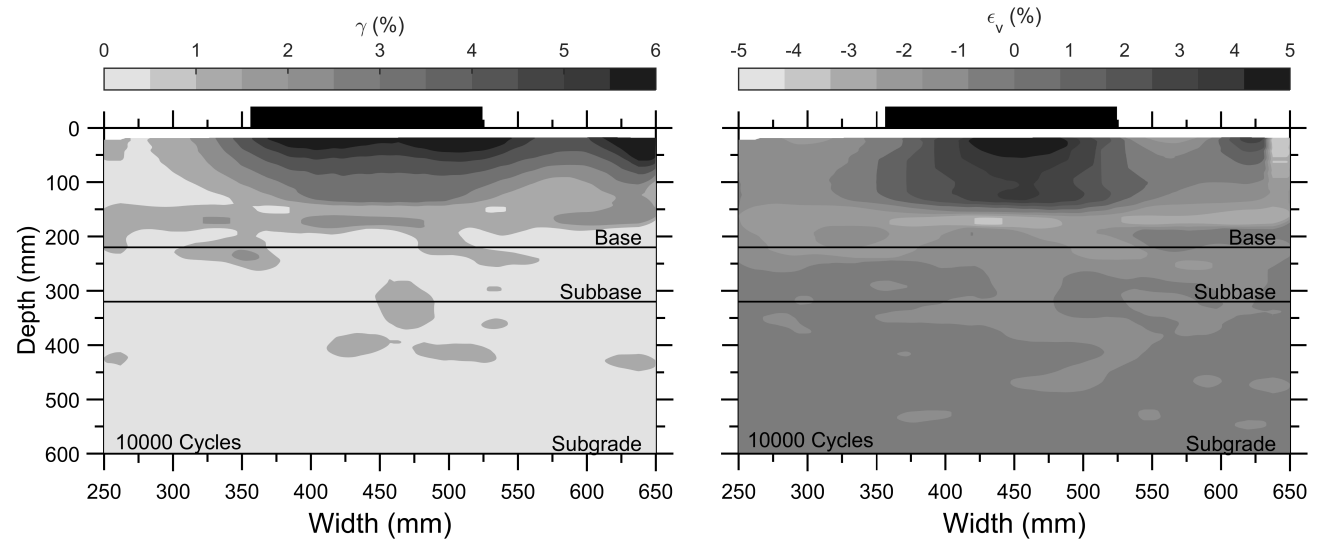

Fig. 10. Shear and volumetric strain contours at 10,000 cycles for Test $1 \mathrm{~A}$
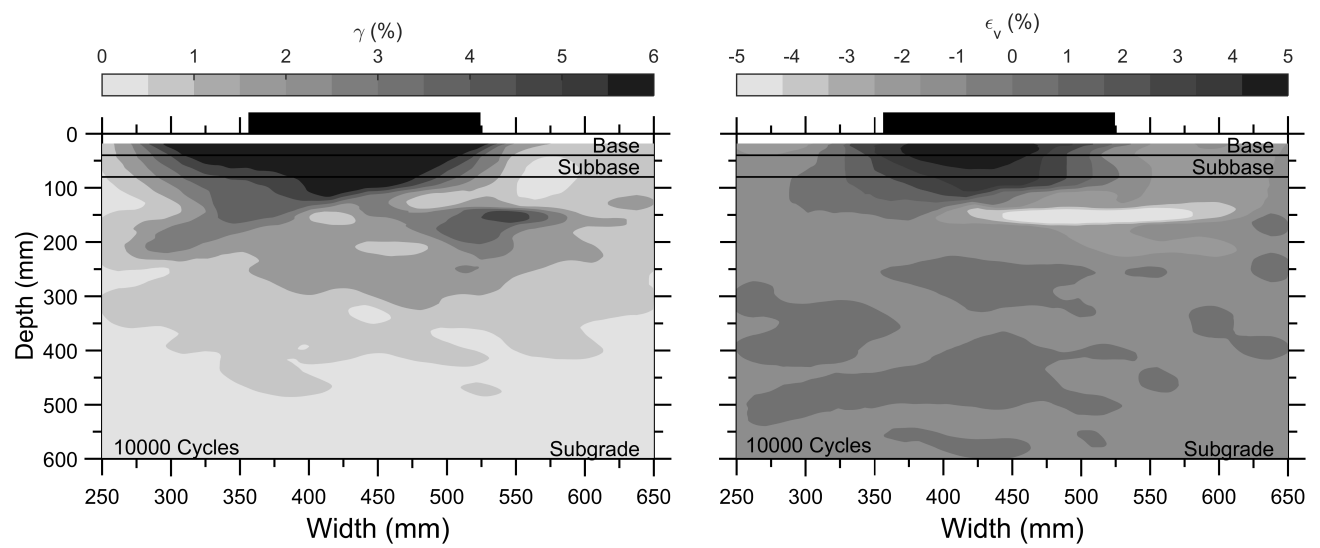

Fig. 11. Shear and volumetric strain contours at 10,000 cycles for Test $2 \mathrm{~A}$

6. The volumetric strain beneath the tyre shows that the base is compressing. At the transition between the base and subbase, the soil dilates, a reaction to the layer beneath and rotation of the stress through the free field. Additional dilation is seen in the passive region on either side of the tyre. This is the cause of the upheaval on either side of the tyre seen in the surface deformation (Figure 6).

In Figure 11 the shear and volumetric strain contours from Test $2 \mathrm{~A}$ at 10,000 cycles are seen. Observations from these results are:

1. The failure planes, which had already extended into the subgrade, were apparent within the first 1,000 cycles.

2. The shear strain is again localised beneath the tyre as in Test 1A. However, the strain is greater, deeper, and the slip planes are more definitive.

3. The angle of the failure wedge to the surface is less than that seen in Test 1A. The rotation of the shear strain failure lines from the the apex of the failure is less than that seen in Test $1 \mathrm{~A}$ as the stress is already in the subgrade.

4. Any effect the base and subbase had on reducing deformation is unclear even at earlier cycles.

5. The volumetric strain is limited to directly beneath the tyre. Some dilation is seen in the plane below the failure cone and to either side of the tyre, but not as horizontal as Test 1A. This explains the lack of heaving on either side of the tyre.

Numerical comparisons between various strain regimes are made in Table 4 at failure, or 17,000 cycles. Unsurprisingly the subsurface shear and volumetric strain of Test $2 \mathrm{~A}$ is substantial compared to that seen in Test $1 \mathrm{~A}$. In all tests, the maximum level of shear strain observed in the base was sufficient to reach critical state. The max shear strain in the subgrade of Test 2A was also enough to achieve critical state. A change in mechanism is apparent by observing the failure angle of the wedge formed beneath the tyre. In the case of Test $1 \mathrm{~A}$, the base course with a $\phi^{\prime}=38^{\circ}$, was thick enough that the frictional behaviour of the material caused a rotation of the plane $\frac{\pi}{4}+\frac{\phi^{\prime}}{2}$. A secondary rotation of the slip plane is seen in the transition between the layers, likely the result of the material change. In Test 2A, the base and subbase had no discernible effect on the rotation of the slip plane, and assuming the subgrade is frictionless, a rotation of $\frac{\pi}{4}$ was more appropriate. These observations prove that not only thickness is a factor to the development of the failure mechanisms, but also that material characteristics play a role.

Utilising these results, the pattern of deformation in the granular material will now be idealised for each test using known collapse mechanisms more typically associated with shallow foundations. Generalising the failure zones as rigid blocks allows engineers to use kinematic plastic solutions and ultimate strength methods to determine capacity, leading to the design of flexible pavements with known factors of safety. The combination of ultimate strength methods and flexible pavement design has been previously suggested (Oloo et al., 1997; Burd \& Freeman, 1997; Collins \& Boulbibane, 2000), but until this point, experimental evidence of the actual slip lines present was missing. 
Table 4. Summary of strain paths beneath tyre at 17,000 cycles

\begin{tabular}{|c|c|c|c|c|}
\hline \multirow[b]{2}{*}{ Layer } & \multicolumn{2}{|c|}{ Test 1A } & \multicolumn{2}{|c|}{ Test 2A } \\
\hline & Base & Subbase & Base & Subgrade \\
\hline $\begin{array}{l}\text { Max shear } \\
\text { strain, } \gamma_{\max }\end{array}$ & $7 \%$ & $1 \%$ & $12 \%$ & $7 \%$ \\
\hline Plane of $\gamma_{\max }$ & $64^{\circ}$ & $160^{\circ}$ & $45^{\circ}$ & $137^{\circ}$ \\
\hline $\begin{array}{l}\text { Max volumetric } \\
\text { strain, } \epsilon_{v_{\max }}\end{array}$ & $6 \%$ & $0 \%$ & $8 \%$ & $5 \%$ \\
\hline $\begin{array}{l}\text { Vertical extent } \\
\text { of } \epsilon_{v}(\mathrm{~mm})\end{array}$ & 151 & - & - & 130 \\
\hline
\end{tabular}

\section{FAILURE MECHANISMS}

Figure 12 shows a variety of relevant failure mechanisms from bearing capacity theory. The sliding block mechanism is simplified from the original mechanism proposed by Prandtl (1920) as a way of developing an equilibrium and kinematically acceptable solution to determine capacity. Techniques used to find the critical failure load from these failure mechanisms include limit analysis, limit equilibrium, and finite elements.
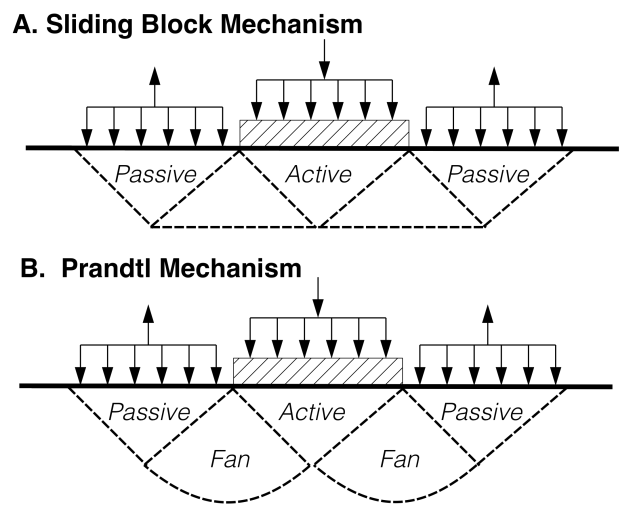

C. Levin Mechanism

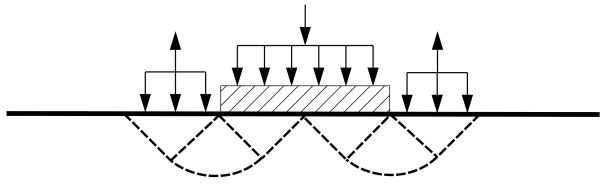

D. Houlsby-Burd Mechanism

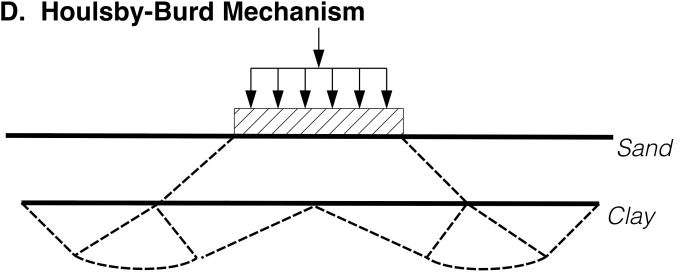

E. Michalowski Continuous Failure Mechanism

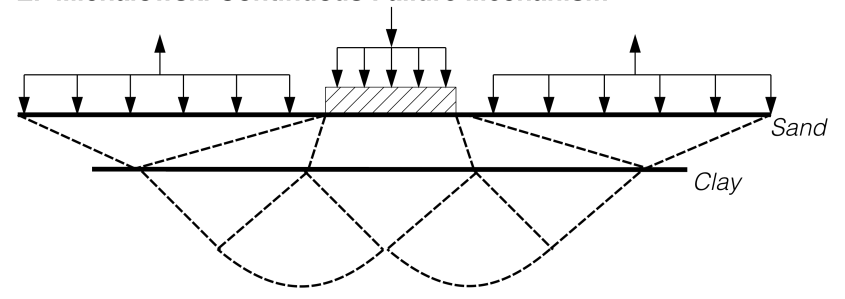

Fig. 12. Half space failure mechanisms
Prandtl (1920) originally assumed the surface load to be a strip foundation acting on a perfectly plastic, cohesive/frictional, weightless, half-space. Since its proposal the concept has been modified, based on theory and experimental data, to account for different footing shapes. Levin (1955) used the geometry seen in Figure 12-B to simulate equal axisymmetric displacements for a smooth circular punch on a halfspace of a perfectly plastic material. Osman \& Bolton (2005) also modified Prandtl (1920) for circular, or axisymmetric, foundations and included strain-hardening behaviour which allowed researchers to connect settlement to stress-strain data observed in triaxial conditions.

Conventional bearing capacity research assumes that the foundation rests on a weak medium surrounded by an infinitely, rigid material. In a pavement, the structural layers are placed above the weaker, in-situ subgrade. Therefore, any appropriate solution for a flexible pavement must include some consideration of the multi-layer soil. Michalowski \& Shi (1995) presented the mechanism seen in Figure 12-E for a strip footing over a two-layer soil and attempted to determine capacity using limit analysis. Houlsby \& Burd (1999), using a load spread model, assumed that the stronger, granular layer, spread the load onto the weaker second-layer, which would then behave as predicted by bearing capacity theory. Overall failure occurred at failure in the lower layer. This mechanism can be seen in Figure 12-D.

A recent review of attempts to apply bearing capacity theory to pavements (Oloo et al., 1997) found that difficulties have stemmed from:

1. ultimate load prediction uncertainty due to layered pavements,

2. environmental variability, and

3. quantification of traffic loading.

Further, it has not yet been established whether a rolling tyre load is best represented by plane strain or axisymmetric conditions (Houlsby \& Burd, 1999). Finally, each of the models described above assumed monotonic loading, which has been shown to not adequately represent the actual cyclic loading found in an actual pavement structure (Brown, 1996; Werkmeister et al., 2001). Collins \& Boulbibane (2000), as a result, has attempted to link bearing capacity with shakedown limit states to better predict the life of the pavement. By experimentally vindicating the mechanical model of deformation at play beneath a flexible pavement any of the above theoretical solutions could be applied. The results of Test $1 \mathrm{~A}$ and Test $2 \mathrm{~A}$ will now be examined to understand if an idealised block mechanism can be found.

\section{Test $1 A$}

Figure 13 reproduces the shear strain contours seen in Figure 10 , however various single layer failure mechanisms have been calculated and overlaid on top of the data to assess applicability. The base is a frictional material and therefore the failure cone beneath the tyre follows the angle $\frac{\pi}{4}+\frac{\phi^{\prime}}{2}=64^{\circ}$ in line with accepted theory. From the apex of the failure cone a circular and logarithmic arc are produced. This represents the region of potential failure paths the shear strain could follow if it were a single material. Traditional soil mechanics would dictate that because the material is drained, the logarithmic arc is the more appropriate prediction for a single layer mechanism. Nevertheless, it can be seen from Figure 13 a better prediction method would necessarily have to adopt a multi-layer geometry.

An example of a potential multi-layer prediction can be seen in Figure 14. The recognised shear surfaces of Figure 13 have been indicated and other supporting lines have been added to 


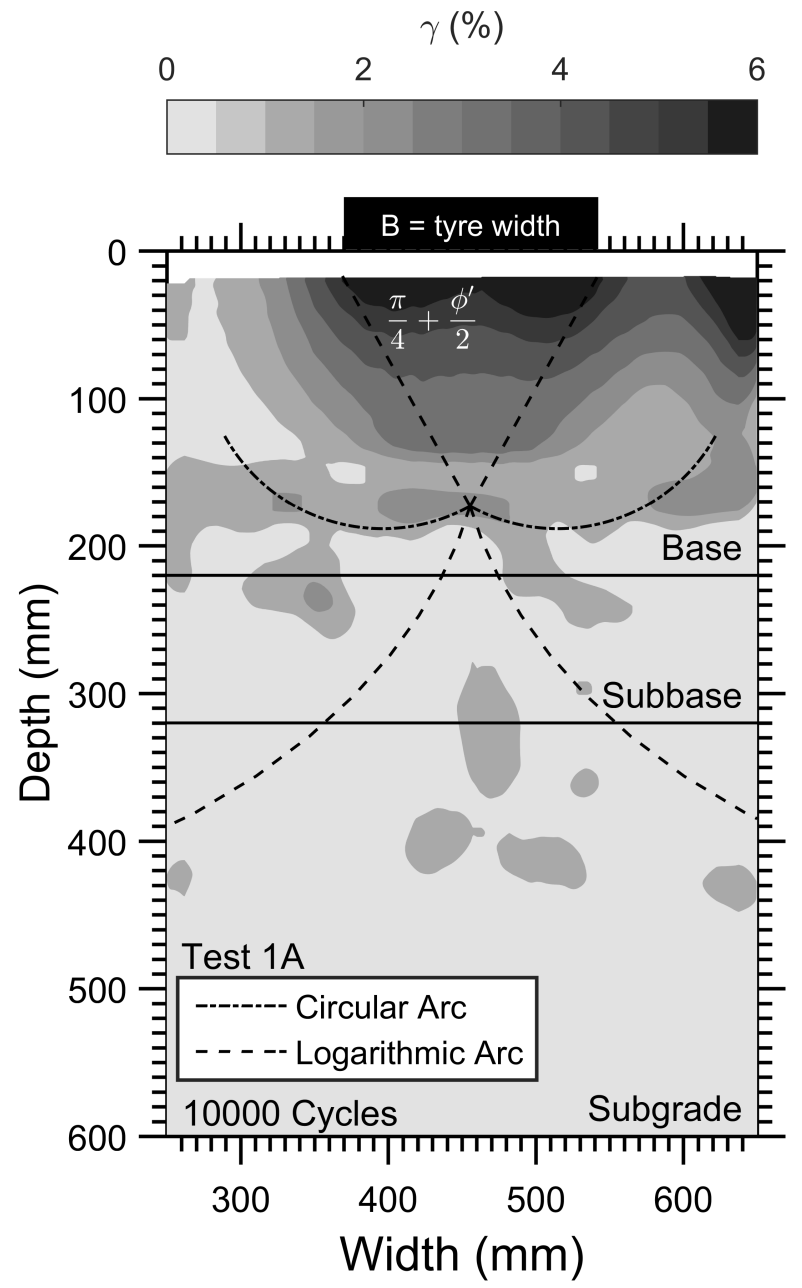

Fig. 13. Failure lines derived from lower bound analysis superimposed on Test 1A shear strain results at 10,000 cycles

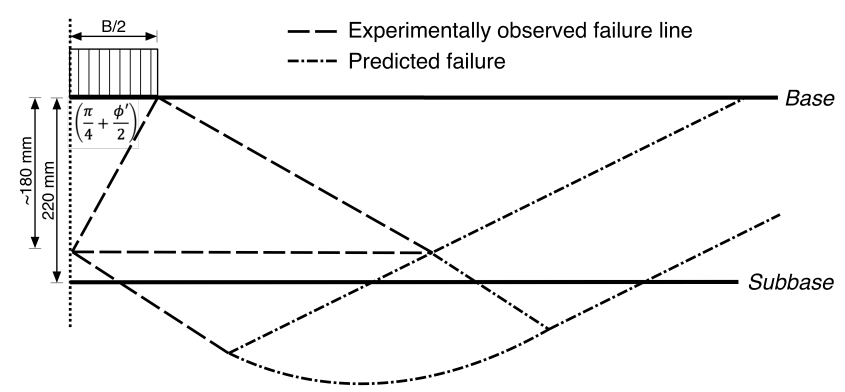

Fig. 14. Deformation mechanism observed in Test 1A

create a kinematically acceptable mechanism. In the base the slip lines are a series of straight lines, based initially on the $\frac{\pi}{4}+$ $\frac{\phi^{\prime}}{2}$. Because the wedge vertex meets within the base, a second horizontal slip lines developed. A second block mechanism is seen below the first, but it is interrupted by the transition from the base to the subbase. Across this discontinuity, formed from the base to the subbase, the original slip plane is rotated because of the change in friction angle across the two soils. Several combinations of the mechanisms seen in Figure 12 could be used to match the slip failures seen in the shear strain data of Test 1A.

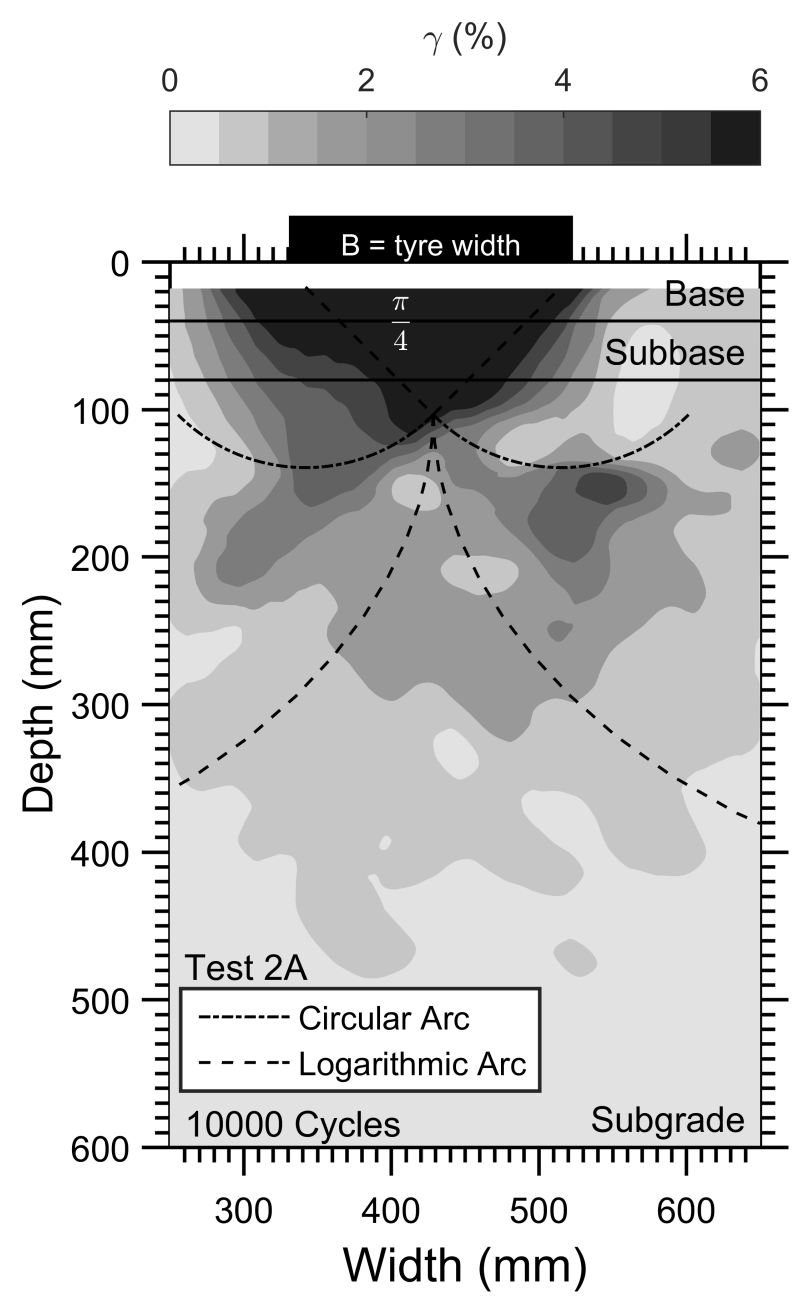

Fig. 15. Failure lines derived from lower bound analysis superimposed on Test $2 \mathrm{~A}$ shear strain results at 10,000 cycles

\section{Test $2 A$}

In Test $2 \mathrm{~A}$, a completely different behaviour is present as a result of the thin structural layers, as shown by Figure 15 . Because the thickness of the base $\left(t_{\text {base }}\right)$ does not meet the criteria laid out in Equation 1, a single layer mechanism using the material properties of the subgrade is appropriate.

$$
t_{\text {base }}<\frac{B}{2} \tan \left(\frac{\pi}{4}+\frac{\phi^{\prime}}{2}\right)
$$

In the case of Test 2A, the subgrade is assumed to be undrained and frictionless. Therefore the angle of the failure cone beneath the tyre is $\frac{p i}{4}$. The arcs beginning at the vertex of the failure cone again show the range the failure slip lines could take. As the subgrade does have some frictional behaviour and the soil is unsaturated it is understandable that the actual slip failures do not match with those predicted by theory.

\section{CONCLUSIONS}

Development of the Cambridge Accelerated Pavement Tester (APT) has, for the first time, allowed the visualisation of the development of subsurface deformations under repeated wheel passes. The APT adds to previous experimental and theoretical work by demonstrating the mechanisms at play beneath a flexible pavement surface. 
Various theoretical mechanisms exist to explain deformation beneath a loaded area, such as a shallow foundation, and observations confirming their validity have been made for monotonic loading on uniform soils. This work extends the existing knowledge to cover the deformations beneath a moving wheel load with many thousands of wheel passes on a layered subsoil. The results suggest that an upper and lower bound mechanism exists and the progression of rutting could be explained using these mechanisms.

The subsurface mechanisms at work are complex, but by combining the results of surface scans and sub-surface DIC data the following generic conclusions can be drawn:

(i) Brown \& Chan (1996) hypothesised that a moving wheel load generates shear stress within the soil causing large, progressive strains to develop. This hypothesis was confirmed by DIC results, which show that surface deformations are the result of an accumulation of subsurface plastic shear and volumetric strains.

(ii) Layer thickness alters deformation behaviour. For thick structural layers, rutting progressed linearly as the number of load applications increased, suggesting a continuous movement of the subsurface material. The substantial upheaval on either side of the rut suggested shearing and subsequent dilation. This was confirmed looking at the subsurface granular movements. Conversely, with thinner surface layers, deformation increased in a non-linear fashion suggesting plastic, progressive failure. The limited upheaval indicated that this failure was occurring primarily beneath the tyre. The subsurface granular movement showed that the failure propagated a substantial distance into the relatively weak subgrade.

(iii) For thin surface layers, the deformation closely resembled an Osman \& Bolton (2005) mechanism for loading of a circular surface foundation. As surface layers became thicker, this mechanism became distorted with a sliding block mechanism occurring in the strong surface layers, underlain by a Houlsby \& Burd (1999) type mechanism in the subgrade soil.

(iv) The permanent deformation of flexible pavements continues to accumulate even over many thousands of cycles of loading.

(v) Using idealised deformation mechanisms, based on those observed here, would simplify the prediction of the cyclic deformation of flexible pavements allowing a more efficient design and optimised for the design-life of the pavement.

\section{REFERENCES}

Boulbibane, M., \& Collins, I. (2015). Development of a pavement rutting model using shakedown theory. International Journal on Pavement Engineering \& Asphalt Technology, 16, No. 1, 55-65.

Bowman, A. \& Haigh, S. (2016). The Cambridge Airfield Pavement Tester. Proceedings of the 3rd European Conference on Physical Modelling in Geotechnics, IFSTTAR, Nantes, France.

Brown, S. (2013). An introduction to asphalt pavement design in the UK. Proceedings of the Institution of Civil Engineers. Transport, 166, No. 4, 189-202.

Brown, S. (1996). Soil mechanics in pavement engineering. Géotechnique, 46, №. 3, 383-426.

Brown, S. \& Chan, F. (1996). Reduced rutting in unbound granular pavement layers through improved grading design. Proceedings of the Institution of Civil Engineers. Transport, 117, No. 1, 40-49.

Burd, H. \& Frydman, S. (1997) Bearing capacity of plane-strain footings on layered soils. Canadian Geotechnical Journal, 34, No. 2, 241-253.

Collins, I. \& Boulbibane, M. (2000). Geomechanical analysis of unbound pavements based on shakedown theory. Journal of
Geotechnical and Geoenvironmental Engineering, 126, No. 1, 5059.

De Beer, M., Fisher, C., \& Jooste, F. (1997). Determination of pneumatic tyre/pavement interface contact stresses under moving loads and some effects on pavements with thin asphalt surfacing layers. Eight (8th) International Conference on Asphalt Pavements (8th ICAP 97), Seattle, Washington, USA. 1, 179-227.

Gräbe, P. \& Clayton, C. (2009). Effects of principal stress rotation on permanent deformation in rail track foundations. Journal of Geotechnical and Geoenvironmental Engineering, 135, No. 4, 555565.

Gopalakrishnan, K. (2010). Forensic investigation of failed airfield test pavements. KSCE Journal of Civil Engineering, 14, No. 3, 395-402.

Houlsby, G. \& Burd, H. (1999). Understanding the behaviour of unpaved roads on soft clay. Proc., 12th Eur. Conf. on Soil Mech. and Geotech. Engrg.Geotech. Engrg. for Transp. Infrastruct., 3142.

Jefferies, M., Shuttle, D., \& Been, K. (2015). Principal stress rotation as cause of cyclic mobility. Geotechnical Research, 2, No. 2, 66-96.

Korkiala-Tanttu, L. (2009). Verification of rutting calculation for unbound road materials. Proceedings of the Institution of Civil Engineers-Transport, 162, No. 2, 107-114.

Lekarp, F., Isacsson, U., \& Dawson, A. (2000) State of the art. I: Resilient response of unbound aggregates. Journal of Transportation Engineering, 126, No. 1, 66-75.

Lekarp, F., Isacsson, U., \& Dawson, A. (2000) State of the art. II: Permanent strain response of unbound aggregates. Journal of Transportation Engineering, 126, No. 1, 76-83.

Lekarp, F. \& Dawson, A. (1998). Modelling permanent deformation behaviour of unbound granular materials. Construction and Building Materials, 12, No. 1, 9-18.

Levin, E. (1955) Indentation pressure of a smooth circular punch. $Q$. Appl. Math. 13, No. 2, 133-137.

Michalowski, R. \& Shi, L. (1995). Bearing capacity of footings over two-layer foundation soils. Journal of Geotechnical Engineering, ASCE, 121, No. 5, 421-428.

Oloo, S., Fredlund, D., \& Julian, K. (1997). Bearing capacity of unpaved roads. Canadian Geotechnical Journal, 34, No. 3, 398407.

Osman, A. \& Bolton, M. (2005) Simple plasticity-based prediction of the undrained settlement of shallow circular foundations on clay. Géotechnique, 55, No. 6, 435-447.

Prandtl, L. (1920) Uber die Hä̈te plastischer Kö̈per. Nachr. Kon̈igl. Ges. Wissensch., Goïtingen; Mathematisch-physikalische Klasse, 74-85.

Qiao, Y., Dawson, A., Huvstig, A., \& Korkiala-Tanttu, L. (2015) Calculating rutting of some thin flexible pavements from repeated load triaxial test data. International Journal of Pavement Engineering, 16, No. 6, 467-476.

Stanier, S., Blaber, J., Take, A., \& White, D. (2015) Improved imagebased deformation measurement for geotechnical applications. Canadian Geotechnical Journal, 53, No. 5, 727-739.

Steyn, W. (2012) Significant findings from full-scale accelerated pavement testing. (Vol. 433). Transportation Research Board

Take, A. (2015) Thirty-Sixth Canadian Geotechnical Colloquium: Advances in visualization of geotechnical processes through digital image correlation. Canadian Geotechnical Journal, 52, No. 9, 1199-1220.

Tawfiq, K. \& Caliendo, J. (1993) Laboratory investigation of polyethylene sheeting as a friction reducer in deep foundation. Geotextiles and Geomembranes, 12, No. 8, 739-762.

Tognon, A., Rowe, R., \& Brachman, R. (1999) Evaluation of side wall friction for a buried pipe testing facility. Geotextiles and Geomembranes, 17, No. 4, 193-212.

Vesic, A. (1963) Bearing capacity of deep foundations in sand. Highway Research Record, No. 39.

Werkmeister, S., Dawson, A., \& Wellner, F. (2001) Permanent deformation behavior of granular materials and the shakedown concept. Transportation Research Record: Journal of the Transportation Research Board, No. 1751, 75-81.

White, D., Take, A., \& Bolton, M. (2003) Soil deformation measurement using particle image velocimetry (PIV) and photogrammetry. Géotechnique, 53, No. 7, 619-632. 